\title{
Scaffolding the Development of English Language and Communication Skills of Engineering Students
}

\author{
Mimi Nahariah Azwani Mohamed ${ }^{1, *}$, Zarina Othman ${ }^{2}$, Suzilla Jamari ${ }^{1}$, Nor Fadhilah Ahmad Powzi ${ }^{1}$, \\ Nurzarina Abd Samad', Nurul 'Ain Othman ${ }^{1}$ \\ ${ }^{1}$ Department of English Language and Linguistics, Centre for Language Studies, Universiti Tun Hussein Onn Malaysia (UTHM), \\ Malaysia \\ ${ }^{2}$ Pusat Citra Universiti, Universiti Kebangsaan Malaysia (UKM), Malaysia
}

Received January 22, 2020; Revised April 1, 2020; Accepted April 21, 2020

Copyright $\bigcirc 2020$ by authors, all rights reserved. Authors agree that this article remains permanently open access under the terms of the Creative Commons Attribution License 4.0 International License

\begin{abstract}
Teaching English in higher institutions is becoming more challenging in this globalised era. With the demand for communication skills in English as one of the important recruitment criteria, future graduates need to be equipped with sufficient English language and communication abilities relevant for their respective fields. This suggests that English language educators need to teach specialised English language such as engineering which may be beyond their expertise. Having trained as English as a second language educators, most of them may have limited knowledge in engineering. This paper is part of a larger research that explores the development of cross-disciplinary curriculum. This study examined the extent to which English language educators addressed the language needs of engineering students academically and professionally. A total of ten language educators from two Malaysian public universities participated in a focus group where they discussed their teaching practices and experiences in teaching engineering students. In addition, six English for Specific Purposes (ESP) practitioners from European universities were also interviewed to obtain information regarding the practices in teaching ESP at their universities. The results show that there is a gap between the development of engineering students' English language abilities in English language classrooms and its maintenance in engineering classrooms in Malaysia. The study highlights the key considerations to develop a framework that scaffolds the development of English language abilities and communication skills among engineering students within engineering education.
\end{abstract}

Keywords ESP, English for Engineering, English Language Teaching, Language and Content, Inter-Disciplinary Teaching, Curriculum Development, Designing English Course

\section{Introduction}

English language teaching in higher education has shifted from teaching general English which focuses on grammar and language structure, to specific English which focuses on language usage in contexts [1]. As such, English language teaching needs to cater to the language needs of students within a particular context or discipline. In order to make learning meaningful, English language teaching needs to be linked to students' disciplinary context, academically as well as professionally. In other words, English language teaching and learning needs to be content-based rather than mere language input classrooms [2].

Recent development in English language teaching in higher education institutions has shown a growing demand for the integration of language and content, focusing on communicative competence [3-5]. Structuring teaching and learning that integrates language and content can be challenging. Arnó-Macià and Mancho-Barés [6] examined the implementation of content and language integrated learning in English for Specific Purposes (ESP) classrooms. The purpose of this approach was to improve students' English language proficiency by learning language in context. The findings showed that the ESP practitioners tend to focus more on the content and less language support. The main issue raised through this study is the challenge for ESP practitioners to balance between content and language in their teaching.

The need to integrate language and content has triggered initiatives to develop and provide ESP-type courses that are domain-specific, such as for engineering [7-9]. In framing their teaching, ESP practitioners need to consider the 
disciplinary variation in the use of English needs to be considered [10]. In other words, English language teaching needs to be domain-specific to enable students to relate to their field of study and participate in their language learning process $[11,12]$. This raises the issue of teaching language discourse appropriate for a particular discipline.

Gilmore and Millar [8] conducted an investigation to identify words commonly used for civil engineering to determine how specialised the words need to be. In their study, they highlighted the discourse commonly used within civil engineering field, particularly in written communication. In another study, Noguera-Díaz and Pérez-Paredes [13] examined the noun phrase modification patterns in a corpus of English for military navy submariners. They found that the English language used for the military navy submariners has distinctive linguistics features, particularly in professional writing and communication. The findings in both studies suggest that language discourse differs from one domain to another and having the knowledge about the "specialised" language for a specific discipline can assist ESP practitioners in managing their language teaching and learning. This raises questions in relation to how much knowledge about the "specialised" language discourse is required of the ESP practitioners. In order to develop knowledge on language discourse for a particular discipline, such as engineering, ESP practitioners should have some basic knowledge about students' field of study [14]. Saliu [15] conducted a study on the challenges that ESP practitioners in one of the European universities faced in teaching ESP. From the interview data, it was found that the ESP practitioners had difficulties in providing the language discourse for engineering as they were not specialists in the students' field of study. In addition, the ESP practitioners were not able to select appropriate materials to address students' language needs in their field of study.

In Malaysia, English language educators who teach at higher learning institutions are generally trained as teachers of English as a second language [16-19]. With the demands for teaching ESP, these English language educators would have to shift from teaching general proficiency to ESP. This shift from English as a second language (ESL) teacher to an ESP practitioner may cause tensions among these English language educators. In their study, Mohamed, Moni and Mills [20] investigated ways in which English language educators positioned themselves when teaching in higher learning institutions. A total of four English language educators from one technical university were interviewed individually. The findings showed that three of the participants struggled in positioning themselves within a discipline-specific context, either to position themselves as an ESL teacher or as an ESP practitioner. They acknowledged the need to integrate English with engineering but lacked confidence in dealing with content knowledge as they were not the experts in that field. This raises questions about the extent to which students' English language needs within their specific fields have been addressed. In addition, there are also questions about the ESL teachers' readiness in teaching the language discourse appropriate for engineering students' academic and workplace contexts.

This study is part of a larger research that aims to develop a framework for cross-disciplinary curriculum between English language and engineering. In this study, the researchers aimed to determine the extent to which English language educators were able to scaffold engineering students in developing English language abilities and communication skills for engineering contexts. In order to achieve this purpose, the experience and teaching practices of English language educators were examined.

\section{Methodology}

This study showcased the complexity of developing engineering students' English language and communication skills for engineering contexts from the English language educators' perspective. The complexity was unpacked through the analysis of the English language educators' experience and teaching practices in addressing the need to teach English for engineering. To achieve this purpose, qualitative approach to data collection was employed as it provided a platform to explore how the English language educators interpret their experience and frame their teaching and learning English for engineering [21].

The study was conducted at three different locations and the participants were English language educators who were second language speakers of English. Two locations were in Malaysia while one location was at a university in Sweden where a group of ESP practitioners gathered for their annual meeting and seminar. The participants were recruited as they were native speakers of English teaching ESP to either English speaking or non-English speaking engineering students. Their experience may provide invaluable insights on teaching ESP from the perspective of native speakers. Five of the participants were from one Malaysian technical university, three of the participants were from one Malaysian public university and five participants were from European universities.

The selection of the participants was through non-probability sampling method where these participants were recruited on a voluntary basis. This sampling method is relevant for this study because the study aimed to provide deep understandings of the issue being investigated and not making generalisation [22]. Although the recruitment of the participants was on a voluntary basis, the researchers also considered the group of students that they teach. In this case, the participants need to be those teaching engineering students. Each participant went through a face-to-face semi-structured interview where the 
questions obtained information related to the participants' conceptualisation of ESP, as well as their experiences and practices in teaching ESP to develop engineering students' English language and communication skills. Each interview lasted for about 45 minutes to one hour. The interview data were transcribed, coded and analysed using thematic analysis. Thematic analysis was employed as it captured the patterns of theme across the dataset [23]. The responses were coded using the coding described in Table 1 below.

Table 1. The description of the code used for the responses

\begin{tabular}{|c|c|}
\hline Code & Description \\
\hline P & Participant \\
\hline E & Europe \\
\hline TH & Participants from the technical university \\
\hline KM & Participants from the public university \\
\hline MPU & Malaysian public university \\
\hline MTU & Malaysian technical university \\
\hline
\end{tabular}

\section{Findings}

In scaffolding the development of their English language and communicative abilities, engineering students need to be able to see the relevance of these skills in their field of study. This requires all stakeholders, particularly the English language instructors to provide meaningful English language learning where students can relate what they learn in an English language classroom to their field of study. Providing such meaningful learning suggests that the English language instructors need to provide specialised language input to these students. Within this context, English language instructors are expected to contextualise their English language courses specifically for engineering. The analysis of the interview data has highlighted the complexity of scaffolding the development of English language and communicative abilities among engineering students for engineering contexts. This complexity includes translating ESP into reality, translating ESP into courses and translating ESP into teaching and learning.

\subsection{Translating ESP into Reality}

Ways in which English language educators conceptualise ESP is crucial as this could affect the achievement of the intended purpose of an ESP course.

ESP refers to teaching specific English language skills to learners with reference to the language needs in their profession. [P1TH1]

Based on these responses, it could be said that the participants understood that ESP courses need to be contextualised according to the students' field of study or future profession, in this case engineering.

The language is tailored for a specific group of learners according to their language needs. [P2TH1]

The language for engineering should be straightforward... they would need language like passive sentences when they talk about process. [P1KM1].

The participants also acknowledged that the language or the sentences used need to be specific for engineering contexts.

...of course English for engineering ... for the general public maybe they will say "the liquid is very thick" but for engineering they may describe the thickness with certain numbers, "the viscosity of the liquid is this...". [P5TH1]

They were aware that English for engineering may differ from English for other contexts.

The courses should focus on developing English communication skills in a specific area such as engineering. [P3TH1]

In addition, the communication skills developed need to be appropriate for engineering field.

...they actually need some input (for example engineering terms) on engineering part...[P1KM2]

One of the participants also indicated that ESP should contain engineering content. However, the above responses were based on their theoretical understanding of what ESP courses should be.

The ESP that we teach is not quite ESP because we tailored our English course for all students (not for specific discipline). We are supposed to tailor the courses to the language needs of their programme.. [P4TH1]

For our course, we do not have ESP in that sense even though this course is for engineering. [P2KM1]

In these responses, it could be observed that there is a gap between what is conceptualised and what is implemented. The ESP courses taught at both universities were found to be general that could be applied to various disciplines. There seems to be a mismatch in translating the concept of ESP that they have understood into their teaching.

We are not required to understand all the engineering stuff. [P3KM1]

I think we are not expected to know everything. [P1KM3]

In both [P3KM1] and [P1KM3] above, the participants, who were from the public university, did not prefer teaching English that included engineering content as they did not have expertise in the field. As a result, their teaching focused more on general skills which could be applied to various disciplines for academic or workplace 
context.

The participants from the technical university, however, demonstrated a different perspective.

I think that the English that we should teach at this university should be tailored to the needs of their programme, in this case, engineering. [P4TH2]

Why should we teach the same English? We should move from easy to difficult because this is the type of English that they are going to use when they go to workplace. [P5TH2]

The two participants above indicated their willingness to teach ESP that is specialised for engineering fields. This indicated their readiness to take up the challenge of including engineering materials or information in their teaching. There was a sense of dissatisfaction for not able to provide the language knowledge and skills that their students need in their field. Based on this finding, it could be observed that the participants intend to translate the way they conceptualise ESP into practice. However, an issue arise on the extent to which this intention has been realised. This issue is discussed in the next section.

\subsection{Translating ESP into the Course Content}

In the previous section, the participants of both Malaysian universities illustrated the complexity in translating their conceptualisation of ESP into practice. They conceptualised the ideal ESP, which is to contextualise the English course into engineering, but reported the reality of ESP teaching at their university. This reality is evident in the ESP courses that are available at their universities.

English for engineering, the content is not engineering content...it's not really technical because we are not engineers... [P2KM3]

In this excerpt, it could be seen that the conceptualisation of an ESP had not been realised. Instead, the content of the courses were common components applicable for various disciplines.

We have English for medical but the content is more on oral presentation. [P2KM5]

We teach them the language input which will be required when they participate in meetings at workplace. [P3KM3]

The common components covered in the ESP courses focused more on communication at workplace such as oral presentations and meetings. This illustrates a mismatch between their belief of an ideal ESP and the courses that they teach or design.

We don't really teach them technical English. [P1KM3]

We don't have expertise in students' field of study. [P3KM2] ...in terms of the engineering terms, I think it is best taught by content lecturers themselves... the (English) course is not so much on technical stuff. [P2KM2]

The participants believed that their role was just to provide the language input as they don't have the expertise in students' field of study. On the one hand, it could be seen that these participants were reluctant to go out of their comfort zone to gain knowledge beyond their expertise. On the other hand, they believed that going beyond the comfort zone was redundant as the content would be covered by the engineering lecturers themselves.

\subsection{Translating ESP into Teaching and Learning}

In the previous two sections, the findings have highlighted the complexity of implementing ESP teaching which is contextualised for engineering. This complexity has led the English language instructors to focus more on general communication skills and language input that are applicable to various disciplines. This suggests that the English language abilities and communication skills developed by the engineering students may not be specifically for engineering contexts. One of the ways to address this issue is to provide teaching and learning that could integrate language and content.

The MPU has started a teaching collaboration between engineering lecturers and English language instructors. This collaboration was initiated by one of the top officers at the university, who were of engineering background.

...this collaboration was a top-down recommendation by our Vice Chancellor...the engineering faculty members were positive about this collaboration. They were also very keen to improve their students' language ability...they wanted their students to perform better. [P3KM2]

This initiation has also inspired the engineering faculty members to participate in the collaboration. In other words, the main players in this collaboration are the engineering faculty members.

I have collaborated with a number of (content) teachers. As long as everyone involved is clear about the intended learning outcomes and who the students are, it works well. [P1E1]

This type of collaboration is also practised by ESP instructors at European higher learning institutions. The main issue that is highlighted by the participant above is clear intended learning outcomes.

I am going to teach with an engineering lecturer soon. And right now, I am excited about it because I like cooperating with this colleague who has been helping me with the dictionary (for engineering students) project. [P3E1]

In [P3E1] above, it could be observed that the ESP instructor from a European university was positive and 
willing to implement this collaboration. He demonstrated the agency to change his teaching approach from teaching "general" ESP to domain-specific ESP. This is to help his students improve their English language and communication skills.

The participants of the MTU, on the other hand illustrated a different perspective when asked about conducting collaborative teaching with the engineering lecturers.

...this (collaborative teaching) is actually a good idea on paper but we as language teachers also need to be familiar with their field. [P4TH3]

It sounds very ideal but we need to see the practicality of it. We need to get information about what they are doing in their field...but it is a good idea to do this. [P5TH3]

Although the participant viewed the collaboration as a good idea, she raised the issue of familiarity of the students' field of study. This is different from the participants from MPU who were not concerned about familiarity of engineering knowledge.

They (engineering lecturers) will look at the content. We will give them input in terms of the language. [P4KM1]

The above excerpt illustrates that both the English language instructors and engineering lecturers at MPU are clear of their roles and the learning outcomes. Within this context, the English language instructors do not need to familiarise themselves with students' field of study. Instead, they only need to understand the language needs of the engineering students.

...(if we were to have this collaboration) we have to meet several times...we have to know the aim...so we are clear of our roles. [P4TH4]

The participant emphasised the importance of understanding the roles of both parties before the collaboration could be conducted and the time needed to set up the collaboration. The issue of time is acknowledged by one of the participants from one European university.

... a great deal of time is needed beforehand for the content teacher and I to agree on how the lesson aims would best be reached. It is not so much about disagreeing on what to teach, but about having clear expectations. [P2E1]

Thorough discussions are required for both the engineering lecturers and the ESP instructors to agree on the learning outcomes that can address students' learning needs of both disciplines. Without the thorough discussions on what are expected of the students to perform and the roles of each instructor, the teaching and learning process may be disrupted.

I remember going to this meeting with people from different engineering departments...at the end of the semester, the students are required to present their projects to the content lecturers and their English instructors. But the engineering lecturers did not discuss with us in terms of the timetable for the presentations. [P2KM3]

The content lecturers also did not consult us about the way the students were expected to present. Some students had to do poster presentation, some had to rap, some had to present in a poetic way and so on. It was difficult for us because on our part we need to assess their oral presentations. [P2KM3]

In the responses above, it could be seen that the collaboration conducted at MPU was biased towards the engineering faulty members. Although there was a meeting conducted to discuss the collaboration, the English language instructors seemed to have limited autonomy over the implementation of the collaboration.

While creating a new practice in teaching and learning is valuable, there is a challenge in sustaining this practice. The people who are directly involved in the collaboration need to be available all the time.

... it is not always sustainable...it is a problem when someone is not available. [P1E2]

Bringing in new partners in the middle of the collaboration may disrupt the teaching and learning process as the partner may not have a clear understanding of the intended learning outcomes.

Another challenge in terms of sustainability is the change in the top management organisational structure. It is a common practice when a new person takes over the management, new policies or practices are introduced while old ones may not be emphasised.

One of the challenges is when the top management changes and the focus on collaboration will also change. And when new instructors join the faculty, they don't know about the collaboration. [P1KM4]

Within this context, a collaboration that was initiated by the previous management may be overlooked or discontinued. Apart from that, new faculty members may not be aware of the existence of the collaboration.

This section has highlighted several issues that need to be considered in creating the eco-system to scaffold the development of English language abilities and communication skills among engineering students. The next section discusses these issues and draws the conclusion.

\section{Discussion}

Providing meaningful English language learning which is contextualised according to learners' field of study such as engineering is complex. The English language educators need to consider ways in which the ESP courses and their teaching could encourage students to engage in meaningful exchanges and facilitate their language learning. Based on 
the findings, there are two main issues that have been highlighted. Firstly, the English language educators may have an understanding of what an ideal ESP course is but may have challenges in translating this understanding into reality. Secondly, designing English language courses and conducting English language teaching which integrate language and content require the English language educators to go beyond their English language expertise and familiarise themselves with engineering knowledge.

When attempting to design ESP courses and frame teaching and learning that integrates language and content, English language instructors may consider applying the $4 \mathrm{C}$ 's framework of communication, content, cognition and culture [24]. Within this framework, language is the medium to express the content, promoting the development of language skills (communication) and construction of knowledge (content and cognition) through social interactions [25]. It is possible to use this framework as the underpinning for a cross-disciplinary curriculum. Nonetheless, the effectiveness of such curriculum lies on the educators' understanding of the main purpose of curriculum. The intended purpose of a curriculum may change through the influence of educators' understandings of the curriculum.

Another alternative to achieve the integration between language and content is to perform collaborative teaching and learning between the English language instructors and the Engineering lecturers. Nonetheless, the findings have raised several key considerations when conducting such collaborations. Firstly, top-down as well as bottom up support is required in order to ensure the continuity of this collaboration. As indicated by the participants at MPU, their collaboration was initiated by the top management and at the same time both the members of the engineering faculties and the English language instructors accepted the initiation positively and implemented the collaboration.

Secondly, both the engineering lecturers and the English language instructors need to be clear about their roles in teaching and assessment, and the intended learning outcomes. This requires both parties to conduct thorough discussions and planning to come to a consensus. Biggs [26] has highlighted three key areas that need to be considered when planning to integrate language and content. These key areas are intended learning outcomes, the teaching and learning process and the assessments. Within this model, English language teaching can have learning outcomes, teaching and learning activities and assessment that are aligned with the content of engineering. The cross-disciplinary collaborative teaching and learning can be made possible with English language and content courses existing separately but with aligned learning outcomes, teaching and learning activities and assessments.

Thirdly, the findings have highlighted the issue of sustainability where one of the people involved in the collaboration are not available, the teaching and learning may be disrupted. As such, a Community of Practice (CoP) needs to be established. According to Lave and Wenger [27], an individual does not learn by himself but through social process that is situated within a cultural and historical context. In other words, educators should learn from one another to frame their teaching better. The establishment of the CoP can provide a platform for the engineering lecturers and English instructors to share their experience and provide information to those who are not directly involved in the collaboration but may be involved in the future. It can also become the platform for newly recruited lecturers or those who have just returned from their study to get updates on what is happening at their faculties.

Lastly, and most importantly, both the English language educators and engineering lecturers need to have the agency to change their approaches in framing their teaching outside their comfort zone. Agency is the element for the instructors to negotiate their practices, and make pedagogical decisions about teaching and learning [28, 29]. In this case, both the English language instructors and engineering lecturers, negotiate their practices and make pedagogical decisions to frame their teaching beyond their expertise.

\section{Conclusion}

This study has highlighted that the key issues that need to be considered when English language instructors attempt to integrate language and content in ESP courses. The discussion on the issues has highlighted the need to consider the aspects of communication, content, cognitive and culture. Apart from that, when there is a need for collaborative teaching, both English language instructors and engineering lecturers need to be clear of their roles in teaching and learning, as well as in assessment. In addition, both parties need to have a clear understanding of the intended learning outcome. On top of that, there is a need to establish the Community of Practise $(\mathrm{CoP})$ to provide a platform for the lecturers to share their experience and to keep updated on what is happening at their faculties in terms of teaching and learning.

In developing English language abilities and communication skills applicable to engineering contexts, engineering students need to have the opportunity to continuously use the English language beyond the English language classrooms. The role of various parties which include the English language educators, engineering lecturers, curriculum and syllabus designers, university administrators, industrial administrators and students is crucial in contributing towards this ecosystem.

\section{Acknowledgements}

The study was funded by the Fundamental Research
Grant Scheme [FRGS/1/2017/SSI09/UTHM/02/4] 
[Vot1648], awarded by the Ministry of Education, Malaysia. The authors would like to express their gratitude to Universiti Tun Hussein Onn Malaysia (UTHM) for the opportunity to obtain this research grant, making this research possible.

\section{REFERENCES}

[1] M. Bracaj, Teaching English for specific purposes and teacher training. European Scientific Journal, Vol. 10, No. 2, pp. 40-49, 2014.

[2] K. Ariffin, M.S. Husin, Code-switching and code-mixing of English and Bahasa Malaysia in content-based classrooms: Frequency and attitudes. The Linguistics Journal, Vol. 4, No. 1, pp. 220-247, 2011.

[3] Y. Ruiz de Zarobe, R. Lyster, Content and language integration in higher education: instructional practices and teacher development. International Journal of Bilingual Education and Bilingualism, Vol. 21, No. 5, pp. 523-526, 2018.

[4] U. Smit, E. Dafouz, Integrating content and language in higher education: An introduction to English-medium policies, conceptual issues and research practices across Europe, in AILA REview, U. Smit and E. Dafouz, Editors. John Benjamin Publishing: Amsterdam. pp. 1-12, 2012.

[5] M. Tzoannopouloua, M., Rethinking ESP: Integrating content and language in the university classroom. Procedia Social and Behavioral Sciences, Vol. 173, pp. 149-153, 2015.

[6] E. Arnó-Macià, G. Mancho-Barés, The role of content and language in content and language integrated learning (CLIL) at university: Challenges and implications for ESP. English for Specific Purposes, Vol. 37, pp. 63-73, 2015.

[7] A. Clement, T. Murugavel, English for employability: A case study of the English language training need analysis for engineering students in India. English Language Teaching, Vol. 8, No. 2, pp. 116-125, 2015.

[8] A. Gilmore, N. Millar, The language of civil engineering research articles: A corpus-based approach. English for Specific Purposes, Vol. 51, pp. 1-17, 2018.

[9] Y. Y. Kovalyova, A.V. Soboleva, A. Kerimkulov, Project based learning in teaching communication skills in English as a foreign language to engineering students. International Journal of Emerging Technologies in Learning, Vol.11, No. 4, pp. 153-156, 2016.

[10] M. Kuteeva, J. Airey, Disciplinary differences in the use of English in higher education: reflections on recent language policy developments. Higher Education, Vol. 67, pp. 533-549, 2013.

[11] C. Baik, J. Greig, Improving the academic outcomes of undergraduate ESL students: the case for discipline-based academic skills programs. Higher Education Research \& Development, Vol. 28, No. 4, pp. 401-416, 2009.

[12] Y. Kirkgöz, Students' and lecturers' perceptions of the effectiveness of foreign language instruction in an English-medium university in Turkey. Teaching in Higher Education, Vol. 14, No. 1, pp. 81-93, 2009.

[13] Y. Noguera-Díaz, P. Pérez-Paredes, Register analysis and ESP pedagogy: Noun-phrase modification in a corpus of English for military navy submariners. English for Specific Purposes, Vol. 53, pp. 118-130, 2019.

[14] J. Mackiewicz, The effects of tutor expertise in engineering writing : A linguistic analysis of writing tutor's comments. IEEE Transactions on Professional Communication, Vol. 47, No. 4, pp. 316-328, 2004.

[15] B. Saliu, Challenges for learners/teachers in the ESP course for legal studies. South East European University Review, Vol. 9, No. 1, pp. 1-8, 2013.

[16] R. Bolitho, Reconceptualising language teacher education for the 21 st century, in the International Conference on English Language and Development for Equity in the 21st Century. 2002: Kuala Lumpur, Malaysia.

[17] M. K. Kabilan, R.I. Raja Izzaham, Challenges faced and the strategies adopted by a Malaysian English language teacher during teaching practice. English Language Teaching, Vol. 1, No. 1, pp. 87-95, 2008.

[18] S. K. Ong, et al. Trainee teachers' perceptions of the school practicum. in The Proceedings of the National Seminar on English Language Teaching. 2004. Bangi.

[19] K. Zeichner, K., Becoming a teacher educator: A personal perspective. Teaching and Teacher Education, Vol. 21, No . 2, pp. 117-124, 2005.

[20] M. N. A. Mohamed, K. Moni, C. Mills, Professional Identity and English Language Teaching in a Discipline-Specific Context, in Current Issues in Second/Foreign Language Teaching and Teacher Development: Research and Practice, C. Gitsaki and T. Alexiou, Editors, Cambridge Scholars Publishing: Newcastle, UK. pp. 85-103, 2015.

[21] S. B. Merriam, Qualitateive research: A guide to design and implementation. 4 ed. 2016, San Fransisco: Jossey-Bass.

[22] V. Vehovar, V. Toepoel, S. Steinmetz, Non-probabality sampling, in The SAGE Handbook of Survey Methodology, C. Wolf, et al., Editors. SAGE Pulication: Los Angeles, 2016.

[23] V. Braun, et al., Thematic Analysis, in Handbook of Research Methods in Health Social Sciences, P. Liamputtong, Editor, Springer: Singapore, pp. 843-860, 2019.

[24] CLIL. Coyle, A pedagogical approach, in Encyclopedia of Language and Education, N.V. Deusen-Scholl and N. Hornberger, Editors. Springer: Boston, M.A. pp. 97-111, 2008.

[25] L. Vilkancience, CLIL in tertiary education: Does it have anything to offer? Studied about Languages, Vol. 18, pp. 111-118, 2011.

[26] J. Biggs, Teaching for quality learning at university - What the student does? . 2nd ed, Buckingham: Open University Press, 2003.

[27] J. Lave, E. Wenger, Situated learning: Legitimate peripheral participation, Cambridge: Cambridge University Press, 
1991.

[28] C. Hao, Changes and characteristics of EFL teachers' professional identity The cases of nine university teachers. Chinese Journal of Applied Linguistics, Vol. 34, No. 1, pp. 3-21, 2011.

[29] P. Hökkä, A. Eteläpelto, H. Rasku-Puttonen, The professional agency of teacher educators amid academic discourses. Journal of Education for Teaching, Vol. 38, No. 1, pp. 102, 2012. 